
\title{
6

\section{Clinical Outcomes of Percutaneous Endoscopic Gastrostomy in the Surgical Intensive Care Unit}

\author{
Gyu Young Pih', Hee Kyong Na ${ }^{1,2}$, Suk-Kyung Hong ${ }^{2,3}$, Ji Yong Ahn', Jeong Hoon Lee', Kee Wook Jung' ${ }^{1}$, Do Hoon Kim ${ }^{1}$, Kee Don \\ Choi $^{1}$, Ho June Song ${ }^{1}$, Gin Hyug Lee ${ }^{1}$ and Hwoon-Yong Jung ${ }^{1}$ \\ ${ }^{1}$ Department of Gastroenterology, Asan Medical Center, University of Ulsan College of Medicine, Seoul, ${ }^{2}$ Nutritional Support Team, \\ Asan Medical Center, Seoul, ${ }^{3}$ Division of Trauma and Surgical Critical Care, Department of Surgery, Asan Medical Center, University of \\ Ulsan College of Medicine, Seoul, Korea
}

Background/Aims: Percutaneous endoscopic gastrostomy (PEG) is usually performed on patients with chronic underlying diseases in the general ward (GW). This study evaluated the clinical outcomes of PEG performed on patients in the surgical intensive care unit (SICU) compared with those of PEG performed in the GW.

Methods: The medical records of 27 patients in the SICU and 263 in the GW, who underwent PEG between January 2013 and July 2017, were retrospectively reviewed.

Results: The median age of the 27 SICU patients was 66 years, and their median body mass index was $21.1 \mathrm{~kg} / \mathrm{m}^{2}$. In the SICU group, the median baseline Sequential Organ Failure Assessment (SOFA) score was 4, and the median Acute Physiology and Chronic Health Evaluation II (APACHE II) score was 16. The median interval between surgery and PEG in SICU patients was 30 days, with a PEG failure rate of 3.7\%. Acute complications in SICU patients included bleeding (7.4\%) and ileus (11.1\%), while chronic complications included aspiration pneumonia (7.4\%) and tube obstruction (3.7\%). The rates of acute and chronic complications did not differ significantly between the SICU and GW groups. The 30 -day mortality rate was $14.8 \%$ in SICU patients and $5.3 \%$ in GW patients $(p=0.073)$.

Conclusions: PEG is a safe and feasible method of enteral feeding for critically ill patients who require ICU care after surgery. Clin Endosc 2020;53:705-712

Key Words: Endoscopy; Gastrostomy; Intensive care unit

\section{INTRODUCTION}

Percutaneous endoscopic gastrostomy (PEG) is usually performed on patients with chronic underlying disease in the general ward (GW). PEG has been reported to be indicated for several chronic neurological diseases such as cerebrovascular disease, Parkinson's disease, dementia, motor neuron disease,

Received: October 4, 2019 Revised: January 11, 2020

Accepted: February 15, 2020

Correspondence: Hee Kyong $\mathrm{Na}$

Department of Gastroenterology, Asan Medical Center, University of Ulsan College of Medicine, 88 Olympic-ro 43-gil, Songpa-gu, Seoul 05505, Korea Tel: +82-2-3010-5676, Fax: +82-2-476-0824, E-mail: hkna77@naver.com ORCID: https://orcid.org/0000-0001-6764-9099

(c) This is an Open Access article distributed under the terms of the Creative Commons Attribution Non-Commercial License (http://creativecommons.org/ licenses/by-nc/3.0) which permits unrestricted non-commercial use, distribution, and reproduction in any medium, provided the original work is properly cited. and specific malignancies. ${ }^{1}$ PEG is the most common method of supplying enteral nutrition to patients expected to require supplementary enteral feeding for longer than 2-3 weeks. ${ }^{2}$ Although it is safe and minimally invasive, few reports have assessed the clinical outcomes of PEG administered to critically ill patients or compared these outcomes in patients who had undergone previous abdominal surgery and those with an intact abdomen. ${ }^{3-8}$ In addition, no study to date has compared the safety and feasibility of PEG in patients in the surgical intensive care unit (SICU) and GW. Accordingly, this study assessed the clinical outcomes of PEG in patients in the SICU who had undergone surgical intervention or were scheduled for surgery, and compared these outcomes with those of patients who underwent PEG in the GW. 


\section{MATERIALS AND METHODS}

\section{Patients}

Of the 324 patients who underwent PEG at the Asan Medical Center (Seoul, Korea) between January 2013 and July 2017, 27 underwent PEG in the SICU and 263 underwent the procedure in the GW. The remaining 34 patients, consisting of 32 who underwent PEG in the medical ICU and two who underwent PEG in the emergency room, were excluded from this study (Fig. 1). Both patients in the emergency room underwent PEG due to cancer progression and were not indicated for surgery. The medical records of all included patients were retrospectively reviewed, and clinical outcomes were compared between SICU and GW patients. Demographic and clinical characteristics were evaluated, including underlying diseases, body mass index (BMI), indications for PEG, complications after PEG, comorbidities, and baseline laboratory values. In addition, baseline Sequential Organ Failure Assessment (SOFA) scores and Acute Physiology and Chronic Health Evaluation (APACHE) II scores for SICU patients were evaluated. Weight and serum albumin concentrations were compared before and after PEG. If post-PEG weight and albumin level were assessed multiple times between 2 weeks and 1 month after PEG, the most recent measurements were used. PEG was performed on patients who had normal gastrointestinal function and were expected to require enteral feeding for longer than 2-3 weeks. The Institutional Review Board (IRB) of Asan Medical Center (Seoul, Korea) approved the study (IRB number, 2018-0928). The requirement for patient informed consent was waived due to the retrospective design of the study.

\section{Percutaneous endoscopic gastrostomy methods}

Of 290 PEG procedures, 289 were performed using the introducer technique and one was performed using the pulltype technique. The PEG procedure was performed by experi- enced gastroenterologists. The introducer (Russell) technique has been the main approach since November 2011, while pulltype PEG is usually performed for the purpose of drainage. The introducer technique was performed using a transilluminated endoscope, and the gastropexy device and trocar were used to penetrate the abdominal wall. A 15-Fr Cliny PEG tube (Create Medic Co., Ltd., Yokohama, Japan) was subsequently inserted directly through the abdominal wall and fixed by filling the balloon of the tube with $5 \mathrm{cc}$ of saline (Fig. 2).

Of 290 patients, 279 (96.2\%) were administered prophylactic antibiotic $30 \mathrm{~min}$ before PEG, with most receiving $2 \mathrm{~g}$ of cefazolin. If a patient was already receiving an antibiotic, an altered regimen was not required unless the current regimen was inappropriate for gram-positive cocci. For sedation, intravenous midazolam $(0.05 \mathrm{mg} / \mathrm{kg})$ and pethidine $(25$ or $50 \mathrm{mg}$ ) were administered before the procedure.

\section{Definitions}

Acute complications were defined as complications that developed within the first 7 days of PEG insertion, and chronic complications were those that occurred after 7 days. Acute complications included bleeding, ileus, pneumoperitoneum, aspiration pneumonia, wound infection, and Mallory-Weiss tear. Chronic complications included tube obstruction, tube leakage, spontaneous tube removal, wound infection, recurrent aspiration pneumonia, and buried bumper syndrome.

Bleeding was defined as a hemorrhagic event requiring endoscopic intervention or embolization for hemostasis and reduction of $>2 \mathrm{~g} / \mathrm{dL}$ of hemoglobin concentration. Aspiration pneumonia was defined as newly developed symptoms, such as cough, purulent sputum, or fever after PEG, in addition to changes in chest X-ray. Diagnosis of ileus was confirmed using $\mathrm{X}$-ray or computed tomography imaging indicative of ileus in addition to decreased bowel sounds with or without symptoms.

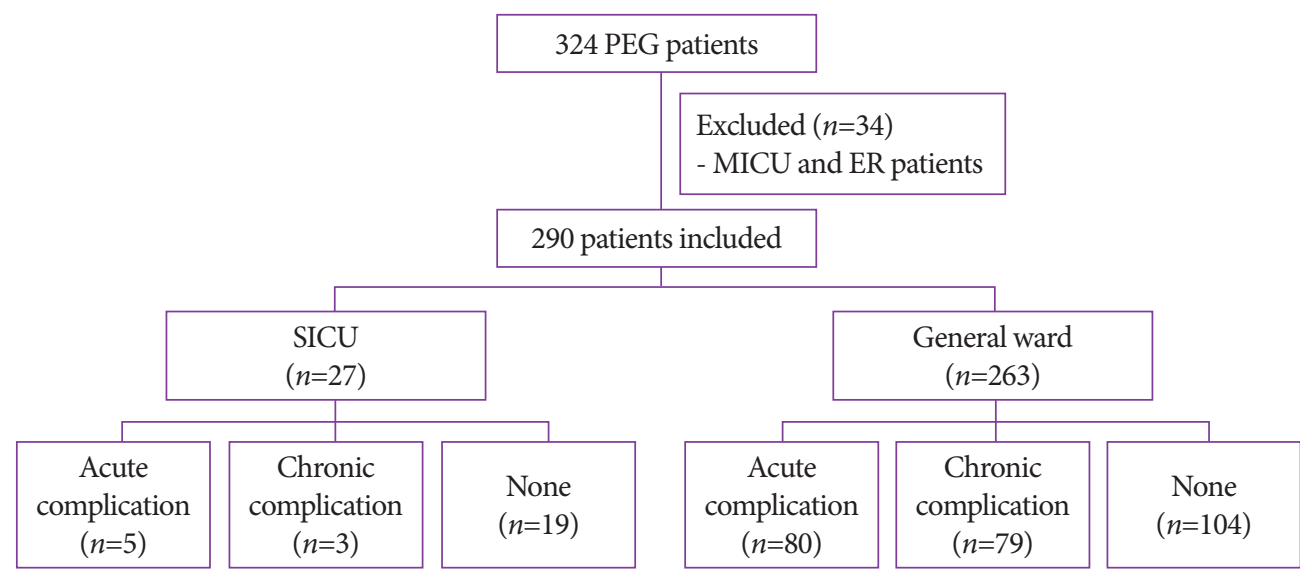

Fig. 1. Study flowchart. ER, emergency room; MICU, medical intensive care unit; PEG, percutaneous endoscopic gastrostomy; SICU, surgical intensive care unit. 

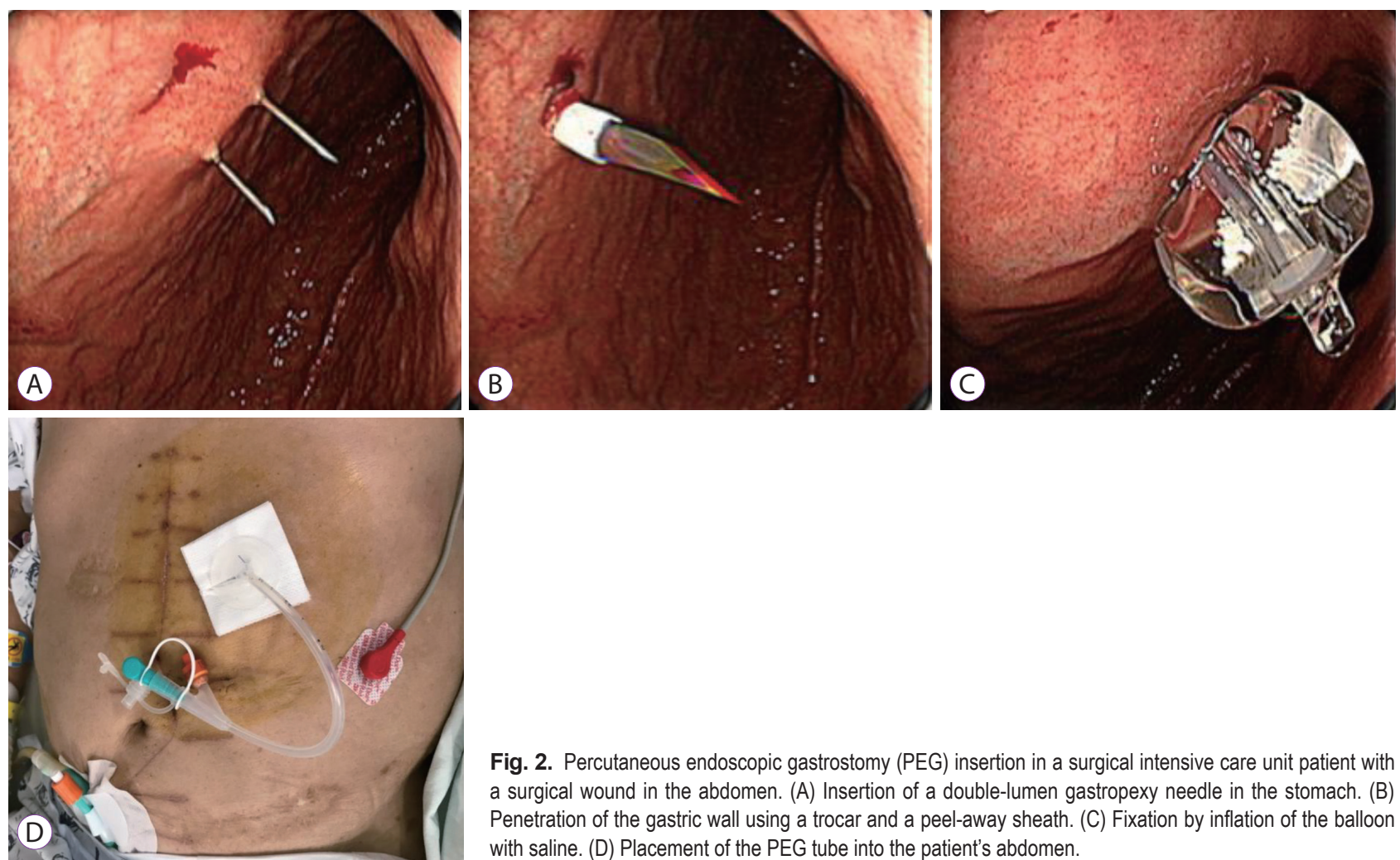

Fig. 2. Percutaneous endoscopic gastrostomy (PEG) insertion in a surgical intensive care unit patient with a surgical wound in the abdomen. (A) Insertion of a double-lumen gastropexy needle in the stomach. (B) Penetration of the gastric wall using a trocar and a peel-away sheath. (C) Fixation by inflation of the balloon with saline. (D) Placement of the PEG tube into the patient's abdomen.

\section{Post-percutaneous endoscopic gastrostomy management}

Patients were kept nil per os on the day of the PEG procedure with natural tube drainage. The next day, the PEG tube of patients with a soft abdomen and those with no abdominal discomfort was flushed with $100 \mathrm{~mL}$ of clear water. After the water flush, patients without abdominal pain, vomiting, or tube leakage started tube feeding with $100-200 \mathrm{~mL}$ of fluid.

Patients in the GW were started on tube feeding with 100 $\mathrm{cc}$ of formulated nutrition, with the volume incrementally increased by $50-100 \mathrm{cc}$ for every meal, as tolerated until the target volume was reached. Patients in the SICU were started on continuous feeding with $20 \mathrm{cc} / \mathrm{hr}$, with the amount increased by $10-20 \mathrm{cc} / \mathrm{hr}$ every $12-24 \mathrm{hr}$ until the target volume was achieved.

\section{Statistical analysis}

Descriptive data are expressed as mean \pm standard deviation for normally distributed continuous variables or as median and interquartile range (IQR). Continuous variables were compared between groups using the $t$ test or Mann-Whitey $U$ test, and categorical variables were compared using the chisquare or Fisher's exact test, as applicable. Multivariate logistic regression models were constructed to evaluate risk factors for complications and 30-day mortality. SPSS version 21.0 (IBM
Co., Armonk, NY, USA) was used for all statistical analyses; differences with a $p$-value $<0.05$ were considered to be statistically significant.

\section{RESULTS}

\section{Baseline characteristics}

The baseline demographic and clinical characteristics of the patients in the GW and SICU groups, including age, sex, BMI, indications for PEG insertion, comorbidities, and baseline laboratory values, are presented in Table 1 . The median age of the 27 SICU patients was 66 years (IQR, 58-77 years), and their median BMI was $21.1 \mathrm{~kg} / \mathrm{m}^{2}$ (IQR, $\left.17.8-24.0 \mathrm{~kg} / \mathrm{m}^{2}\right)$.

The median baseline SOFA score of the SICU patients was 4 (IQR, 3-9), and their median APACHE II score was 16 (IQR, 12-22) (Table 2). Indications for surgery in the SICU group included nine $(33.3 \%)$ patients with traumatic fracture with brain hemorrhage and four (14.8\%) with malignancy including mouth floor cancer, distal common bile duct cancer, hepatocellular carcinoma, and sigmoid colon cancer. Four (14.8\%) patients had panperitonitis. The mean interval from surgery for panperitonitis to the PEG procedure was 36.2 days. Patients exhibited improving clinical course of panperitonitis but presented other postoperative complications, such as ven- 
Table 1. Baseline Characteristics of Patients Who Underwent Percutaneous Endoscopic Gastrostomy Insertion

\begin{tabular}{|c|c|c|c|}
\hline & General ward $(n=263)$ & SICU $(n=27)$ & $p$-value \\
\hline \multicolumn{4}{|l|}{ Clinical characteristics } \\
\hline Age, median (IQR) & $70(61-79)$ & $66(58-77)$ & 0.268 \\
\hline Sex, male & $174(66.2 \%)$ & $20(74.1 \%)$ & 0.405 \\
\hline BMI, median (IQR) & $18.9(16.8-21.1)$ & $21.1(17.8-24.0)$ & 0.003 \\
\hline Indications for PEG, $n(\%)$ & & & 0.020 \\
\hline Neurologic disease & $154(58.6 \%)$ & $14(51.9 \%)$ & \\
\hline Malignancy & $73(27.8 \%)$ & $4(14.8 \%)$ & \\
\hline Other & $36(13.7 \%)$ & $9(33.3 \%)$ & \\
\hline \multicolumn{4}{|l|}{ Comorbidities, $n(\%)$} \\
\hline Hypertension & $109(41.4 \%)$ & $13(48.1 \%)$ & 0.502 \\
\hline Diabetes mellitus & $70(26.6 \%)$ & $6(22.2 \%)$ & 0.621 \\
\hline Chronic kidney disease & $13(4.9 \%)$ & $3(11.1 \%)$ & 0.177 \\
\hline Antibiotic prophylaxis, $n(\%)$ & $254(96.6 \%)$ & $25(92.6 \%)$ & 0.273 \\
\hline \multicolumn{4}{|l|}{ Concurrent medication, $n(\%)$} \\
\hline Aspirin & $38(14.4 \%)$ & $5(18.5 \%)$ & 0.571 \\
\hline Clopidogrel & $25(9.5 \%)$ & $5(18.5 \%)$ & 0.176 \\
\hline Warfarin & $10(3.8 \%)$ & $1(3.7 \%)$ & 1.000 \\
\hline \multicolumn{4}{|l|}{ Laboratory data } \\
\hline WBC, $\mu \mathrm{L}$ & $7,200(5,800-10,000)$ & $7,600(5,400-9,900)$ & 0.825 \\
\hline Hemoglobin, g/dL & $11.0(9.6-12.4)$ & $8.4(7.6-9.1)$ & $<0.001$ \\
\hline Platelet, $10^{3} / \mu \mathrm{L}$ & $251(191-319)$ & $261(143-338)$ & 0.888 \\
\hline Albumin, g/dL & $2.8(2.4-3.3)$ & $2.3(1.9-2.6)$ & $<0.001$ \\
\hline $\mathrm{C}$-reactive protein, $\mathrm{mg} / \mathrm{dL}$ & $1.4(0.4-4.2)$ & $1.8(1.2-6.0)$ & 0.015 \\
\hline Procedure time, $\min$ & $18.6 \pm 7.2$ & $17.8 \pm 7.3$ & 0.332 \\
\hline
\end{tabular}

BMI, body mass index; IQR, interquartile range; PEG, percutaneous endoscopic gastrostomy; SICU, surgical intensive care unit; WBC, white blood cell.

tilator-associated pneumonia and cerebral infarction, which lengthened hospital stay. Seven (25.9\%) patients underwent surgery for other conditions including abdominal aorta aneurysm, total hip replacement arthroplasty, infective endocarditis, kidney transplantation rejection, simultaneous pancreas kidney transplantation, and ulcerative colitis. Three patients in the SICU did not undergo any surgical intervention. One patient was admitted to the SICU due to a traffic accident and was diagnosed with brain death. A second patient was admitted to the SICU after falling and sustaining an intracerebral hemorrhage; after undergoing a tracheostomy and being treated for pneumonia, he was transferred to a local hospital. The third patient had undergone a kidney transplant and was admitted to the SICU for suspicion of acute rejection. She was treated medically for the rejection without surgical intervention.

\section{Clinical outcomes}

The median interval between surgery and PEG in the SICU group was 30 days (IQR, 19-51 days), and the median follow-up period was 73 days (IQR, 21-189 days). PEG insertion was successful in 26 of the 27 patients in the SICU. PEG insertion was unsuccessful in one (3.7\%) patient due to the inability of the needle to puncture the gastric wall. Repeated surgical procedures in this patient may have led to the development of postoperative anatomic distortion. This patient had undergone a subtotal colectomy for an ischemic colitis induced perforation with panperitonitis and had underlying end-stage renal failure. After the colectomy, she underwent additional anastomosis revision and ileostomy due to anastomosis site leakage. Three weeks after surgery, respiratory arrest occurred due to aspiration. PEG in this patient failed.

Post-PEG complications are summarized in Table 3. Acute complications in SICU patients included bleeding (7.4\%) and 
Table 2. Clinical Characteristics of Surgical Intensive Care Unit Patients

\begin{tabular}{ll}
\hline APACHE II score (median) & $16(\mathrm{IQR}, 12-22)$ \\
\hline SOFA score (median) & $4(\mathrm{IQR}, 3-8)$ \\
\hline Vasopressor & $3(11.1 \%)$ \\
\hline $\begin{array}{l}\text { Indication for surgery } \\
\text { Traumatic fracture with brain hemorrhage }\end{array}$ & $9(33.3 \%)$ \\
Traumatic fracture without brain hemorrhage & $1(3.7 \%)$ \\
Malignancy & $4(14.8 \%)$ \\
Panperitonitis & $4(14.8 \%)$ \\
Others (UC, THRA, AAA, IE, KT rejection, & $6(22.2 \%)$ \\
$\quad$ SPKT) & $3(11.1 \%)$ \\
No surgery & $10(37.0 \%)$ \\
Abdominal surgery & 4 \\
Bowel resection (small bowel resection and & \\
$\quad$ colectomy) & 2 \\
Transplantation (KT and SPKT) & 4 \\
Others (lobectomy, primary repair of cystic duct & 4 \\
stump, PPPD, AAA surgery) & $30(\mathrm{IQR}, 19-51)$ \\
\hline Interval between surgery and PEG, days (median)
\end{tabular}

AAA, abdominal aorta aneurysm; APACHE, Acute Physiology and Chronic Health Evaluation; IE, infective endocarditis; IQR, interquartile range; KT, kidney transplantation; $\mathrm{PEG}$, percutaneous endoscopic gastrostomy; PPPD, pyloric preserving pancreaticoduodenectomy; SOFA, Sequential Organ Failure Assessment; SPKT, simultaneous pancreas and kidney transplantation; THRA, total hip replacement arthroplasty; UC, ulcerative colitis.

Table 3. Complications in General Ward and Surgical Intensive Care Unit Patients

\begin{tabular}{lccc}
\hline & $\begin{array}{c}\text { General ward } \\
(\boldsymbol{n}=\mathbf{2 6 3})\end{array}$ & $\begin{array}{c}\text { SICU } \\
(\boldsymbol{n}=\mathbf{2 7})\end{array}$ & $\boldsymbol{p}$-value \\
\hline Acute complications & & & \\
Bleeding & $23(8.7 \%)$ & $2(7.4 \%)$ & 1.000 \\
Pneumoperitoneum & $30(11.4 \%)$ & $0(0.0 \%)$ & 0.090 \\
Ileus & $27(10.3 \%)$ & $3(11.1 \%)$ & 0.749 \\
Chronic complications & & & \\
Wound infection & $13(4.9 \%)$ & $0(0.0 \%)$ & 0.618 \\
Leakage & $16(6.1 \%)$ & $0(0.0 \%)$ & 0.378 \\
Tube obstruction & $34(12.9 \%)$ & $1(3.7 \%)$ & 0.222 \\
Spontaneous removal & $12(4.6 \%)$ & $0(0.0 \%)$ & 0.611 \\
Buried bumper syndrome & $1(0.4 \%)$ & $0(0.0 \%)$ & 1.000 \\
Aspiration pneumonia & $3(1.1 \%)$ & $2(7.4 \%)$ & 0.070 \\
\hline
\end{tabular}

SICU, surgical intensive care unit. ileus (11.1\%), and chronic complications included aspiration pneumonia (7.4\%) and tube obstruction (3.7\%). The incidence rates of acute and chronic complications did not differ significantly between the GW and SICU groups.

Of the four SICU patients who developed bleeding, none required intervention to stop the bleeding. By comparison, five patients in the GW group underwent endoscopic intervention, such as clipping, coagrasper, or embolization, to stop the bleeding. Ileus was detected in three patients in the SICU group, and all patients exhibited improvement following conservative management.

Of the 27 patients in the SICU group, 12 were discharged to the GW, seven were transferred to local hospitals, and eight died during SICU admission. All 12 patients discharged to the GW were fed through PEG tubes; their median length of stay in the SICU was 53 days (IQR, 25-75 days). The median length of stay in the SICU for all 27 patients was 57 days (IQR, 28-83 days). The median interval from surgery to PEG insertion in patients with intra-abdominal surgery was 46 days (IQR, 20-71 days).

Nine patients (33.3\%) were able to have their PEG tube removed and resume oral feeding. The median interval of PEG use in these nine patients was 37 days (IQR, 25-75 days).

\section{Prognosis}

Clinical prognosis after PEG insertion, including early mortality rate and nutritional status, is summarized in Table 4 . The 30 -day mortality rate in the SICU group was $14.8 \%$, which was considerably higher than the $5.3 \%$ in the GW group. However, none of the patients in the SICU group died of procedure-related causes. Four patients in the SICU group died within 30 days of the PEG procedure. One of these patients was admitted

Table 4. Prognosis of General Ward and Surgical Intensive Care Unit Patients after Percutaneous Endoscopic Gastrostomy Insertion

\begin{tabular}{lccc}
\hline & $\begin{array}{c}\text { General ward } \\
(\boldsymbol{n}=\mathbf{2 6 3})\end{array}$ & $\begin{array}{c}\text { SICU } \\
(\boldsymbol{n}=\mathbf{2 7})\end{array}$ & $\boldsymbol{p}$-value \\
\hline Follow-up period, days & $252 \pm 16$ & $159 \pm 44$ & 0.078 \\
$\begin{array}{l}\text { Nutrition status } \\
\quad \begin{array}{l}\text { Mean weight change } \\
\text { after PEG, kg }\end{array}\end{array}$ & $0.14 \pm 3.46$ & $-0.59 \pm 3.66$ & 0.472 \\
$\quad \begin{array}{c}\text { Mean BMI change after } \\
\text { PEG }\end{array}$ & $0.04 \pm 1.35$ & $-0.25 \pm 1.32$ & 0.411 \\
$\begin{array}{c}\text { Mean albumin level } \\
\text { change after PEG, g/dL }\end{array}$ & $0.17 \pm 0.59$ & $0.33 \pm 0.54$ & 0.419 \\
\hline \begin{tabular}{l}
30 day mortality \\
\hline
\end{tabular} & $14(5.3 \%)$ & $4(14.8 \%)$ & 0.073 \\
\hline
\end{tabular}

BMI, body mass index; PEG, percutaneous endoscopic gastrostomy; SICU, surgical intensive care unit. 
to the SICU due to a traffic accident and was diagnosed with brain death. The second patient underwent intra-abdominal surgery after being transferred to the SICU for panperitonitis and died 15 days after PEG from aggravated ischemic colitis. A third patient with rectal cancer and multiple lung metastases was admitted to the SICU for drug-induced lung injury; this patient died of aggravated pneumonia 3 days after PEG. The fourth patient, who had ischemic colitis and underwent a right hemicolectomy and cholecystectomy, developed pneumonia and ventricular tachycardia and died of cardiac arrest 8 days after PEG insertion.

Fourteen patients in the GW group died within 30 days after PEG, including one from PEG procedure-related causes. This patient died 12 days after PEG insertion of newly developed aspiration pneumonia. Four patients died of aspiration pneumonia not related to the PEG. Other causes of death included renal failure, acute myocardial infarction, traumatic subdural hemorrhage, and sepsis due to urinary tract infection. Five patients died of unknown causes, because they were lost to follow-up.

Mean changes in weight, BMI, and serum albumin concentration from before to after PEG insertion did not differ significantly in the GW and SICU groups.

\section{DISCUSSION}

PEG has been commonly administered as a method of enteral feeding for patients with chronic medical conditions. Nutritional support is important for both critically ill patients and postoperative patients, and recent systematic reviews of randomized trials found that 'nil by mouth' following gastrointestinal surgery yielded no obvious advantage, and recommended early enteral feeding. ${ }^{9-11}$ Appropriate nutritional support can benefit critically ill patients by improving wound healing and reducing complication rates and length of stay. ${ }^{12}$

Currently, there are no standard guidelines or indications for PEG in patients in the GW and in critically ill patients. Although PEG is a safe and minimally invasive procedure, no risk factors have been consistently found to determine candidates for PEG procedures. Despite its introduction in the 1980s, PEG is administered to relatively few patients in the ICU, and clinical trials of PEG have included only small numbers of patients.

While few studies have assessed outcomes of PEG insertion for patients in the ICU, PEG has been reported to be safe and effective for critically ill patients in an ICU, with low rates of procedure-related morbidity and mortality. ${ }^{3-5}$ However, to our knowledge, the present study was the first to compare clinical outcomes of PEG insertion in SICU and GW patients.

The SICU patients had a median baseline SOFA score of 4 (IQR, 3-9) and a median APACHE II score of 16 (IQR, 12-22). A significant cutoff point for SOFA score has not yet been established, although SOFA score cutoffs in predicting mortality are reported to range from 2 to $7 .^{13-15}$ APACHE II score cutoffs of 10-24 are reported to have high sensitivity and specificity in predicting clinical outcomes. ${ }^{16-18}$ Considering the roles of SOFA and APACHE II scores in determining disease severity, the SICU patients in the present study were regarded as having moderately severe disease.

The present study found that PEG was a successful nutritional method in patients who underwent abdominal surgery, including small bowel resection, colectomy, pyloric-preserving pancreaticoduodenectomy, liver lobectomy, and kidney transplantation, and that these patients maintained PEG without major complications. Moreover, the rates of acute and chronic complications related to PEG did not differ significantly between SICU and GW patients. A previous study comparing PEG in ICU patients with no previous abdominal surgery and those with recent or previous laparotomy found no significant differences in complication rates of bleeding, PEG dislodgment, and wound complication. ${ }^{7}$ Although critically ill patients in the ICU and SICU are vulnerable to infection, ${ }^{19,20}$ the present study found that the rates of wound complications did not differ significantly between the SICU and GW groups. Antibiotic prophylaxis has been reported to be successful in preventing peristomal wound infection. . $^{21,22}$

In addition, postoperative ileus is a frequent complication following gastrointestinal and other types of surgery and is associated with patients' morbidity and clinical outcomes. ${ }^{23}$ In the present study, the rates of ileus after PEG were comparable between the GW (10.3\%) and SICU (11.1\%) groups. In a previous study, early enteral nutrition after gastrointestinal surgery was associated with significantly less ileus. ${ }^{24}$ Although ileus is one of the potential complications of PEG, early enteral nutrition may provide some benefit, but should be selected after considering potential clinical benefits and harms.

Similar to a study demonstrating that no patients in the neurosurgical ICU experienced procedure-related complications, the rate of complications, including bleeding and pneumoperitoneum, was lower in SICU patients than in GW patients, although the difference was not statistically significant. ${ }^{5} \mathrm{Com}$ parisons of the complication and mortality rates in the GW and SICU groups revealed that PEG was safe and effective in providing nutritional support.

The reported success rate of PEG in patients who previously underwent surgery range from $88 \%$ to $94.7 \%{ }^{25,26}$ Anatomic deformity after surgery and intra-abdominal adhesions may 
affect the success rate of PEG insertion. Eleftheriadis et al. emphasized the importance of transillumination and finger indentation observed during endoscopy for successful PEG. ${ }^{6}$ In addition, previous research reported complications of gastrocolic and colocutaneous fistulas. ${ }^{27,28}$ However, in the present study, no patient experienced fistulas penetrating other organs or the skin.

Limitations of the present investigation are mainly associated with its retrospective design. First, this study was conducted at a tertiary referral hospital, where disease severity is higher than at general hospitals. Second, the number of SICU patients was much smaller than that of the GW patients. However, this study is the first to report clinical outcomes of PEG in SICU patients and may inform further studies involving postoperative and critically ill patients. Large randomized controlled trials are required to confirm the efficacy of PEG for patients who undergo surgical interventions.

In conclusion, PEG was a safe and feasible method of enteral feeding for critically ill patients in the SICU. Before PEG insertion, anatomic deformities caused by surgical interventions should be considered. Transillumination and finger indentation during PEG insertion are important to its success.

Conflicts of Interest

The authors have no financial conflicts of interest.

Author Contributions

Conceptualization: Hee Kyong Na

Data curation: HKN, Suk-Kyung Hong, Ji Yong Ahn, Jeong Hoon Lee, Kee Wook Jung, Do Hoon Kim, Kee Don Choi, Ho June Song, Gin Hyug Lee, Hwoon-Yong Jung

Formal analysis: Gyu Young Pih

Investigation: GYP

Methodology: HKN, JYA

Project administration: HKN

Resources: SKH, JHL, KWJ, DHK, KDC, HJS, GHL, HYJ

Supervision: HKN, HYJ

Visualization: GYP

Writing-original draft: GYP

Writing-review\&editing: HKN, JYA

ORCID

Gyu Young Pih: https://orcid.org/0000-0002-6051-8691

Suk-Kyung Hong: https://orcid.org/0000-0001-5698-0122

Ji Yong Ahn: https://orcid.org/0000-0002-0030-3744

Jeong Hoon Lee: https://orcid.org/0000-0002-0778-7585

Kee Wook Jung: https://orcid.org/0000-0002-3771-3691

Do Hoon Kim: https://orcid.org/0000-0002-4250-4683

Kee Don Choi: https://orcid.org/0000-0002-2517-4109

Ho June Song: https://orcid.org/0000-0001-9255-1464

Gin Hyug Lee: https://orcid.org/0000-0003-3776-3928

Hwoon-Yong Jung: https://orcid.org/0000-0003-1281-5859

\section{REFERENCES}

1. Rahnemai-Azar AA, Rahnemaiazar AA, Naghshizadian R, Kurtz A, Farkas DT. Percutaneous endoscopic gastrostomy: indications, technique, complications and management. World J Gastroenterol 2014;20:77397751.

2. Löser C, Aschl G, Hébuterne X, et al. ESPEN guidelines on artificial enteral nutrition--percutaneous endoscopic gastrostomy (PEG). Clin Nutr 2005;24:848-861.

3. Zippi M, Fiorani S, De Felici I, et al. Percutaneous endoscopic gastrostomy (PEG) in critically ill patients performed at bed in intensive care unit: report of our experience. Clin Ter 2009;160:359-362.

4. Ferraro F, Gravina AG, d'Elia A, et al. Percutaneous endoscopic gastrostomy for critically ill patients in a general intensive care unit. Acta Gastroenterol Belg 2013;76:306-310.

5. Koc D, Gercek A, Gencosmanoglu R, Tozun N. Percutaneous endoscopic gastrostomy in the neurosurgical intensive care unit: complications and outcome. JPEN J Parenter Enteral Nutr 2007;31:517-520.

6. Eleftheriadis E, Kotzampassi K. Percutaneous endoscopic gastrostomy after abdominal surgery. Surg Endosc 2001;15:213-216.

7. Guzzo JL, Bochicchio GV, Haan J, Bochicchio K, Kole K, Scalea TM. Percutaneous endoscopic gastrostomy in ICU patients with previous laparotomy. Am Surg 2005;71:420-423.

8. Pih GY, Na HK, Ahn JY, et al. Risk factors for complications and mortality of percutaneous endoscopic gastrostomy insertion. BMC Gastroenterol 2018;18:101.

9. Andersen HK, Lewis SJ, Thomas S. Early enteral nutrition within $24 \mathrm{~h}$ of colorectal surgery versus later commencement of feeding for postoperative complications. Cochrane Database Syst Rev 2006;(4):CD004080.

10. Herbert G, Perry R, Andersen HK, et al. Early enteral nutrition within 24 hours of lower gastrointestinal surgery versus later commencement for length of hospital stay and postoperative complications. Cochrane Database Syst Rev 2019;7:CD004080.

11. Lewis SJ, Andersen HK, Thomas S. Early enteral nutrition within $24 \mathrm{~h}$ of intestinal surgery versus later commencement of feeding: a systematic review and meta-analysis. J Gastrointest Surg 2009;13:569-575.

12. Heyland DK. Nutritional support in the critically ill patients. A critical review of the evidence. Crit Care Clin 1998;14:423-440.

13. Mazzola P, Bellelli G, Perego S, et al. The sequential organ failure assessment score predicts 30-day mortality in a geriatric acute care setting. J Gerontol A Biol Sci Med Sci 2013;68:1291-1295.

14. Safari S, Shojaee M, Rahmati F, et al. Accuracy of SOFA score in prediction of 30-day outcome of critically ill patients. Turk J Emerg Med 2016;16:146-150.

15. Jentzer JC, Bennett C, Wiley BM, et al. Predictive value of the sequential organ failure assessment score for mortality in a contemporary cardiac intensive care unitpopulation. J Am Heart Assoc 2018;7:e008169.

16. Grmec S, Gasparovic V. Comparison of APACHE II, MEES and Glasgow Coma Scale in patients with nontraumatic coma for prediction of mortality. Acute Physiology and Chronic Health Evaluation. Mainz Emergency Evaluation System. Crit Care 2001;5:19-23.

17. Wang IK, Wang ST, Chang HY, et al. Prognostic value of acute physiology and chronic health evaluation II and organ system failure in patients with acute renal failure requiring dialysis. Ren Fail 2005;27:663-669.

18. Huang J, Xuan D, Li X, Ma L, Zhou Y, Zou H. The value of APACHE II in predicting mortality after paraquat poisoning in Chinese and Korean population: a systematic review and meta-analysis. Medicine (Baltimore) 2017;96:e6838.

19. To KB, Napolitano LM. Common complications in the critically ill patient. Surg Clin North Am 2012;92:1519-1557.

20. Sawyer RG, Leon CA. Common complications in the surgical intensive care unit. Crit Care Med 2010;38(9 Suppl):S483-S493.

21. Lockett MA, Templeton ML, Byrne TK, Norcross ED. Percutaneous endoscopic gastrostomy complications in a tertiary-care center. Am Surg 
2002;68:117-120.

22. Ahmad I, Mouncher A, Abdoolah A, et al. Antibiotic prophylaxis for percutaneous endoscopic gastrostomy--a prospective, randomised, double-blind trial. Aliment Pharmacol Ther 2003;18:209-215.

23. Bragg D, El-Sharkawy AM, Psaltis E, Maxwell-Armstrong CA, Lobo DN. Postoperative ileus: recent developments in pathophysiology and management. Clin Nutr 2015;34:367-376.

24. Boelens PG, Heesakkers FF, Luyer MD, et al. Reduction of postoperative ileus by early enteral nutrition in patients undergoing major rectal surgery: prospective, randomized, controlled trial. Ann Surg 2014;259:649655 .
25. Foutch PG, Talbert GA, Waring JP, Sanowski RA. Percutaneous endoscopic gastrostomy in patients with prior abdominal surgery: virtues of the safe tract. Am J Gastroenterol 1988;83:147-150.

26. Townsend MC, Flancbaum L, Cloutier CT, Arnold MW. Early postlaparotomy percutaneous endoscopic gastrostomy. Surg Gynecol Obstet 1992;174:46-48.

27. Stellato TA, Gauderer MW, Ponsky JL. Percutaneous endoscopic gastrostomy following previous abdominal surgery. Ann Surg 1984;200:4650.

28. Yamazaki T, Sakai Y, Hatakeyama K, Hoshiyama Y. Colocutaneous fistula after percutaneous endoscopic gastrostomy in a remnant stomach. Surg Endosc 1999;13:280-282. 